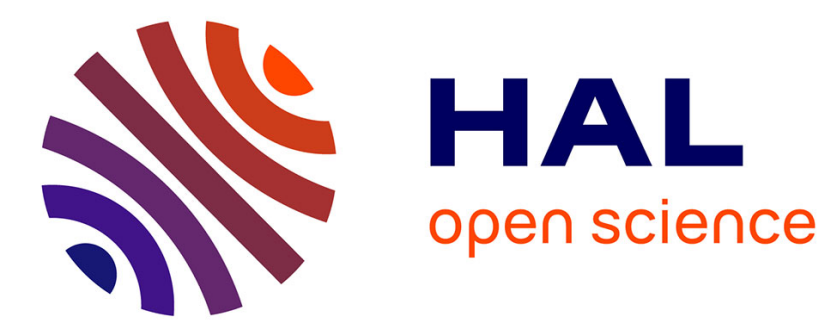

\title{
Plastisol Gelation and Fusion Rheological Aspects
}

Jacques Verdu, Agnes Zoller, Antonio Marcilla

\section{To cite this version:}

Jacques Verdu, Agnes Zoller, Antonio Marcilla. Plastisol Gelation and Fusion Rheological Aspects. Journal of Applied Polymer Science, 2013, 129, pp.2840-2847. 10.1002/app.39005 . hal-01059306

\section{HAL Id: hal-01059306 https://hal.science/hal-01059306}

Submitted on 29 Aug 2014

HAL is a multi-disciplinary open access archive for the deposit and dissemination of scientific research documents, whether they are published or not. The documents may come from teaching and research institutions in France or abroad, or from public or private research centers.
L'archive ouverte pluridisciplinaire HAL, est destinée au dépôt et à la diffusion de documents scientifiques de niveau recherche, publiés ou non, émanant des établissements d'enseignement et de recherche français ou étrangers, des laboratoires publics ou privés. 


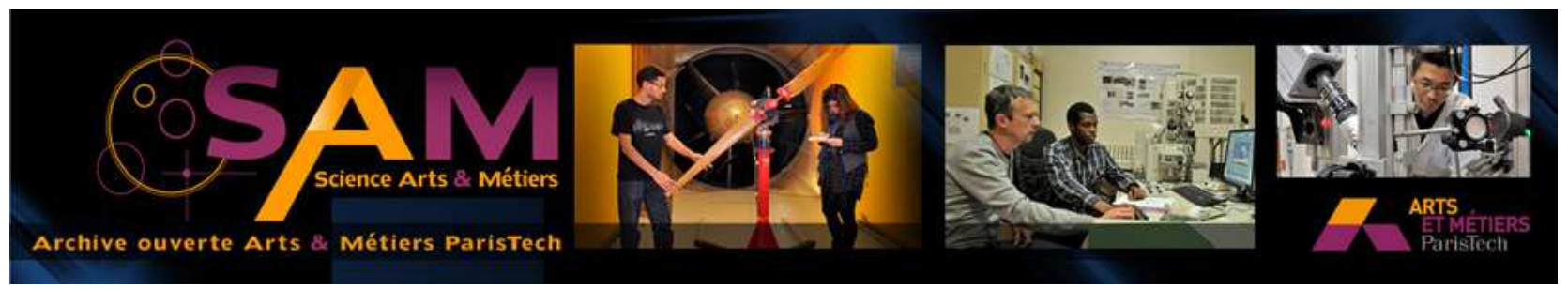

Science Arts \& Métiers (SAM)

is an open access repository that collects the work of Arts et Métiers ParisTech researchers and makes it freely available over the web where possible.

This is an author-deposited version published in: http://sam.ensam.eu Handle ID: .http://hdl.handle.net/10985/8419

\section{To cite this version :}

Jacques VERDU, Agnes ZOLLER, Antonio MARCILLA - Plastisol Gelation and Fusion Rheological Aspects - Journal of Applied Polymer Science - Vol. 129, p.2840-2847 - 2013 


\title{
Plastisol Gelation and Fusion Rheological Aspects
}

\author{
Jacques Verdu, ${ }^{1}$ Agnes Zoller, ${ }^{2}$ Antonio Marcilla ${ }^{2}$ \\ ${ }^{1}$ Arts et Métiers ParisTech, 151 bd de I'HOPITAL, 75013 Paris, France \\ ${ }^{2}$ Department of Chemical Engineering of the University of Alicante, Apartado 99 Alicante, Spain \\ Correspondence to: A. Marcilla (E-mail: antonio.marcilla@ua.es)
}

\begin{abstract}
This study deals with the rheological aspects of poly-vinyl chloride (PVC) plastisol gelation and fusion processes in foamable formulations. Here, such processes are simulated by temperature-programmed experiment $\left(5 \mathrm{~K} \mathrm{~min}^{-1}\right)$ in which complex viscosity components are continuously recorded. Nineteen samples based on a PVC-VAC (vinyl acetate 95/5) copolymer with 100 phr plasticizer have been studied, differing only by the plasticizer structure. The sample shear modulus increases continuously with temperature until a maximum, long time after the end of the dissolution process as characterized by DSC. The temperature at the maximum varies between 345 and $428 \mathrm{~K}$ with a clear tendency to increase almost linearly with the plasticizer molar mass, and to vary with the flexibility and the degree of branching of the plasticizer molecule. The shear modulus increase is interpreted in terms of progressive "welding" of swelled particles by polymer chain reptation. The plasticizer nature would mainly affect the friction parame-ter of chain diffusion.
\end{abstract}

\section{INTRODUCTION}

There are many types of processing operations (foaming, rotomolding, etc.) in which poly-vinyl chloride (PVC) plastisols are heated from ambient temperature to about $200 \pm 20^{\circ} \mathrm{C}$. An interesting peculiarity of these materials is that their viscosity, $\eta^{*}$, and their shear modulus, $G$, vary in a nonmonotonic way during such experiments. ${ }^{1,2}$ The viscosity first decreases until a minimum located at a temperature $T_{\min }$ of about $40-50^{\circ} \mathrm{C}$. Then both the modulus and the viscosity increase to reach a maximum at the temperature $T_{\max }$. During this episode, the material adopts a rubbery behavior.

In its initial state, the plastisol can be described as a suspension of rigid PVC particles in a liquid plasticizer. It is thus expected to behave as a molecular liquid, and its viscosity is expected to be a decreasing function of temperature as effectively observed. $^{1-5}$ This state is characterized by two main features: the existence of an aging process revealed by a viscosity increase during isothermal exposure, ${ }^{1}$ and the fact that the duration of the period to reach $T_{\min }$ is an increasing function of the particle size and depends of the plasticizer nature. For many authors, an important property in this period is the plasticizer "compatibility," in other words the reciprocal polymer-plasticizer solubility as expressed for instance in terms of Flory's interaction parameter $\chi^{1,6}$ or more complex structural factors. ${ }^{5}$ Surprisingly, plasticizer diffusivity D in the polymer (which is not necessarily correlated with solubility) is often ignored or just mentioned among many other factors, whereas it seems to us the key parameter in this context. As a matter of fact, plasticizer penetration in PVC is expected to obey the "case II" diffusion" according to which the plasticizer invades progressively PVC particles with an abrupt diffusion front separating the fully plasticized superficial layer and the unplasticized core. This front moves progressively toward the particle center. In such process, the kinetics of the solvation process is expected to depend more on diffusion than on equilibrium (solubility) parameters. The initial plastisol morphology is also characterized by the presence of agglomerates and by the roughness of elementary particles. It has been suggested that particle deagglomeration and plasticizer penetration in particle anfractuosities may also play an important role. ${ }^{1}$ These processes, whatever their mechanism is, justify the number of articles reporting microscopic investigations. ${ }^{1,3,5,9-11}$

In this article, phenomena occurring at $T<T_{\min }$ will not be considered, which explains why, in the experiments, temperature scans begin at $40^{\circ} \mathrm{C}$ rather than at ambient temperature.

Above $T_{\min }\left(\sim 50^{\circ} \mathrm{C}\right)$, both the storage modulus $\mathrm{G}$ and the viscosity $\eta^{*}$ increase more or less abruptly until a maximum located at a temperature $T_{\max }$ ranging between about 60 and $150^{\circ} \mathrm{C}$ depending of many factors among which is the plasticizer nature. There is a wide consensus to call it "gelation" although 
the nature of the physical crosslinking mechanism responsible for this process is not clearly identified in most articles. "Gelation" could be first associated to the loss of tackiness, ${ }^{1}$ that is, presumably to the disappearance of the liquid phase constituted of almost pure plasticizer. It is also possible to associate "gelation" to the disappearance of the granular morphology. ${ }^{1,11-13}$ However, rheological measurements of $T_{\min }$ considered as the temperature of the onset of "gelation" and $T_{\max }$ where "gelation" is generally considered complete, are the most common ways for characterizing this phenomenon. ${ }^{1-5,14,15}$. In most cases, the curve $G=f(T)$ displays a shoulder in the vicinity of the glass transition temperature $\left(T_{\mathrm{g}}\right)$ of the unplasticized polymer $\left(\sim 80^{\circ} \mathrm{C}\right)$, indicating that, at this temperature, the plasticizer has not yet penetrated into the particle core. The system can be thus described, in this intermediary state, as a suspension of rigid particles having a soft, swollen $\operatorname{skin}^{16,17}$ in the liquid plasticizer. The viscosity increase could be caused by the progressive increase in particle size because of swelling. ${ }^{18}$ A very interesting and complete description of the rheological changes experienced by PVC plastisols at constant and at increasing temperatures was presented by Boudhani et al. ${ }^{19}$ In this article, the evolution of the complex viscosity with time was related to the solid volume fraction of a system with swelling particles reaching the percolation threshold.

Above $T_{\max }$, both the modulus and the viscosity decrease continuously with temperature and the material tends to adopt a behavior characteristic of a macromolecular liquid. Here also, there is a wide consensus to call this phenomenon "fusion." Just above $T_{\max }$, the granular morphology is no more observable. It is necessary to reach temperatures $T_{\text {fin }}$ of, typically, $200 \pm 20^{\circ} \mathrm{C}$ to obtain acceptable tensile properties. ${ }^{9,20}$ If the material is not treated at the adequate temperature and time, it may easily break at ambient temperature. In their study of the PVC-epoxyester systems, Fenollar et al. $^{9}$ determined the curing time to achieve the maximum sample ductility (ultimate elongation of the order of $250 \%$ at ambient temperature), it was about 16 $\min$ at $180^{\circ} \mathrm{C}, 12 \mathrm{~min}$ at $200^{\circ} \mathrm{C}$, and $5 \mathrm{~min}$ at $220^{\circ} \mathrm{C}$. For many authors, ${ }^{1,9,20}$ the "fusion" process is associated to the existence of PVC micro-crystallites ${ }^{21}$ of which the melting would be needed to allow complete material homogenization. To our opinion, a similar behavior would be observed with a fully amorphous polymer; this is the reason why we have chosen to study a vinyl chloride-vinyl acetate copolymer of especially low crystallinity. But the main objective of this article is to bring new results on the effect of plasticizer structure on the "gelation-fusion" process. Some partial results have been reported in literature, for instance on five plasticizers among which were one phthalate, two sebacates, and two phosphates ${ }^{1}$; four alkyl phthalates ${ }^{3}$; one adipate, one phthalate, and one citrate $^{5}$; three phthalates, one mellitate, and their mixtures; ${ }^{6}$ or three alkyl phthalates ${ }^{10}$. As quoted above, these results were generally interpreted in terms of solvent-polymer (equilibrium) interactions. It seemed to us interesting to study a larger series of 19 plasticizers (of distinct structures) in order to have a more panoramic view of the influence of factors such as aliphatic/aromatic content (alkyl adipates and alkyl phthalates), degree of branching (citrates and esters of erythritol), and molecular or macromolecular (polyadipates) character on the processes under study.

\section{EXPERIMENTAL}

\section{Materials}

The resin (ETINOX 400 supplied by ASCONDEL) was a vinyl chloride-vinyl acetate copolymer (95/5). Its $K$-value was 70 and its glass transition temperature $T_{\mathrm{gp}}$ measured by DSC was $81.4^{\circ} \mathrm{C}$. It was stabilized by a Ca-Zn stearate (REAGENS) $2 \mathrm{phr}$ combined with epoxidized soybean oil (Lankroflex $2307 \quad 6$ phr).The plasticizers under study are listed in Table I.

The polymer and stabilizers were thoroughly mixed with each plasticizer $(100 \mathrm{phr})$ at room temperature in a rapid mixer at $120 \mathrm{~min}^{-1}$ during $5 \mathrm{~min}$ of the series. Mixtures were then degassed for $15 \mathrm{~min}$ under vacuum (pressure $\leq 100 \mathrm{~Pa}$ ).

\section{Characterization}

Both components of complex shear viscosity were measured in a Bohlin CS 50 viscosimeter in temperature-programmed conditions: from $40^{\circ} \mathrm{C}$ to $180^{\circ} \mathrm{C}$ at $5^{\circ} \mathrm{C} \mathrm{min}^{-1}$, under nitrogen. This range of temperature covers the main processes typically occurring in PVC plastisol processing before decomposition starts. The plane-plane configuration with plateau diameter of $20 \mathrm{~mm}$ and a gap of $0.5 \mathrm{~mm}$ was used. The rheological properties were recorded at constant $5 \times 10^{-3}$ strain amplitude and $1 \mathrm{~Hz}$ frequency.

\section{RESULTS}

The variations of complex viscosity $(\eta)$, storage shear modulus $\left(G^{\prime}\right)$, and loss modulus $\left(G^{\prime \prime}\right)$ are shown in Figures 1 and 2 for the plastisols prepared with DEP, DOP, and DUP. For DOP all the three quantities are very low at temperatures lower than $80^{\circ} \mathrm{C}$. Then they increase until a maximum located at around $130-140^{\circ} \mathrm{C}$, to decrease above this temperature. All the samples behave in the same way but with maxima depending of the plasticizer nature, as illustrated by the curves of complex viscosity (Figure 1) and storage and shear modulus (Figure 2) against temperature for phthalates having the lowest molar mass (DEP) and the highest molar mass (DUP) (note the different values attained by the different plasticizers). The characteristics of the curves maxima are given in Table II.

It clearly appears that all the samples behave as molecular liquids (for the frequency under study: $1 \mathrm{~Hz}$ ) below $80^{\circ} \mathrm{C}$ and above $180^{\circ} \mathrm{C}$. Between these limits they behave rather as a viscoelastic fluid in a more or less sharp temperature interval, with a maximum located at a temperature increasing with molar mass and a maximum modulus value decreasing with molar mass, at least in the phthalate series.

The coordinates of maximum of $\mathrm{G}^{\prime}$ are listed in Table III for all plasticizers under study.

The temperature where the maximum value of the storage modulus was reached $\left(T_{\max }\right)$ is plotted in Figure 3 for all plasticizers except the polymeric ones.

In the phthalate family [filled (linear) and empty (branched) squares in Figure 3], the dependence is not far from a straight line of equation (in $\mathrm{K}$ ):

$$
T_{\max }=276.5+0.312 \mathrm{M}
$$


Table I. Code, Commercial Name, Density, Molar Mass, and Supplier of the Plasticizers Under Study

\begin{tabular}{|c|c|c|c|c|c|}
\hline Name & Code & Commercial name & Density $\left(\mathrm{kg} \mathrm{m}^{-3}\right)$ & Molar mass & Producer \\
\hline Diethyl phthalate & DEP & Palatinol A & 1118 & 222 & BASF \\
\hline Heptyl undecyl phthalate & HUP & Palatinol 7-11 P & 971 & 418 & BASF \\
\hline Nonylundecyl phthalate & NUP & Palatinol 9-11 P & 958 & 450 & BASF \\
\hline Diundecyl phthalate & DUP & Palatinol 11 & 953 & 475 & BASF \\
\hline Diisobutyl phthalate & DIBP & Palatinol IC & 1039 & 278 & BASF \\
\hline Diisoheptyl phthalate & $\mathrm{DIHP}$ & Jayflex 77 & 991 & 362 & EXXON \\
\hline Diethylhexyl phthalate & DOP & Palatinol DOP & 983 & 391 & BASF \\
\hline Diisononyl phthalate & DINP & Palatinol N & 973 & 421 & BASF \\
\hline Dihexyl adipate & $\mathrm{DHA}$ & Plastomoll DHA & 935 & 314 & BASF \\
\hline Diisononyl adipate & DINA & Plastomoll DNA & 922 & 398 & BASF \\
\hline Polyadipate & PA3 & Palamoll 652 & 1050 & 3300 & BASF \\
\hline Polyadipate & PA7 & Palamoll 632 & 1145 & 7000 & BASF \\
\hline Acetyl tributyl citrate & ATBC & Citroflex A4 & 1050 & 402 & Morflex \\
\hline Acetyl trihexyl citrate & ATHC & Citroflex A6 & 1050 & 486 & Morflex \\
\hline Alkyl sulfonic esters ${ }^{a}$ & ASE & Mesamoll ASE & 1055 & 368 & BASF \\
\hline Benzene dicarboxylate ${ }^{\mathrm{b}}$ & EHBDC & Eastman TM 168 & 984 & 391 & Eastmaan \\
\hline Cyclohexane diester ${ }^{\mathrm{C}}$ & $\mathrm{DINCH}$ & Hexamoll DINCH & 949 & 425 & BASF \\
\hline Pentaaerythritol ester ${ }^{d}$ & H 600 & Hercoflex 600 & 1000 & 604 & Hercules \\
\hline Pentaerythritol ester ${ }^{\mathrm{e}}$ & H 707 & Hercoflex 707 & 1000 & 750 & Hercules \\
\hline
\end{tabular}

a Mixture of esters. ${ }^{b} B i s\left(2 e t h y l h e x y l-1-4\right.$ benzene dicarboxylate. ${ }^{c}$ Diisononyl cyclohexane 1-2 dicarboxylate. ePentaerythritol esters of fatty acids of molar mass approximately $600(4)$ and $750(5) \mathrm{g} \mathrm{mol}^{-1}$.

$T_{\max }$ increases to about $4.4 \mathrm{~K}$ per carbon added to the aliphatic chain that is very close to previously found values. ${ }^{1}$

Adipate points (filled circles) and esters of pentaerythritol are clearly above this straight line. Citrates (empty circles) are below. Plasticizers named as others: ASE and EHBC and DINCH lye close to the line of the phthalates. Linear polyadipates constitute a separate family of which $T_{\max }$ is apparently independent of molar mass (not shown in Figure 3). In fact, all plasticizers except the polyadipates and the esters of pentaerythritol could be well fitted by a single straight line as that shown in Figure 3 as discontinuous line, very similar to that of the phthalates, but with a logically larger dispersion.

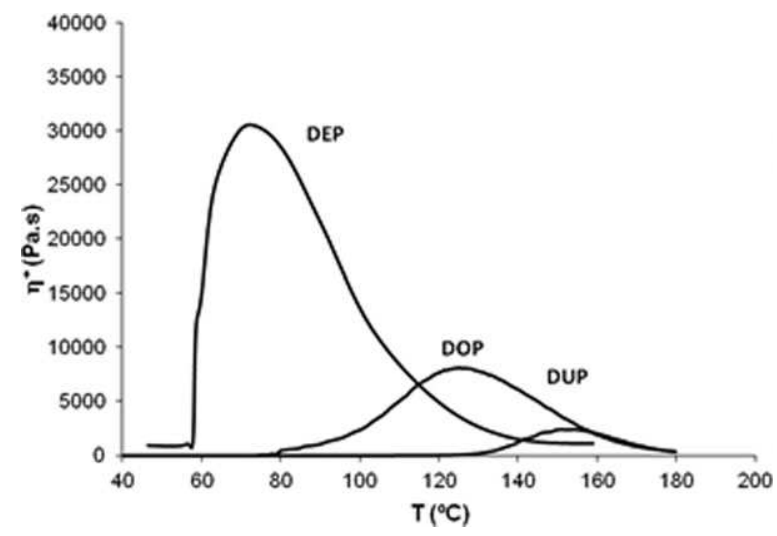

Figure 1. $\eta^{*}$ (Pa.s) versus temperature for the plastisol prepared with DEP, DOP, and DUP.
The number of points for the plasticizer families other than phthalates is too small to envisage suitable structure-property relationships.

The meaning of eq. (1) is not easy to explain, but it allows predicting $T_{\max }$ values in the phthalate series with a relatively good accuracy.

The difference between both linear (difunctional) families could be linked to the molecular flexibility: aliphatic structures (adipates) are more flexible than aromatic structures (phthalates).

The slight discrepancies observed for aromatic structures other than phthalates can be understood: sulfone groups increase

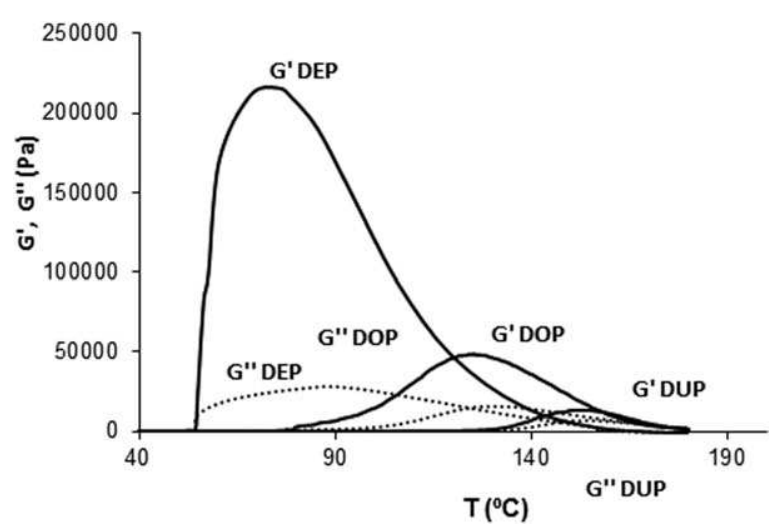

Figure 2. $\mathrm{G}^{\prime}$ (continuous line) and $\mathrm{G}^{\prime \prime}$ (dotted line) (Pa) versus temperature for the plastisol prepared with DEP, DOP, and DUP. 
Table II. Characteristics of the Maximum of $\mathrm{G}^{\prime}$ for Three Phthalates

\begin{tabular}{llll}
\hline Sample & $M(\mathrm{~g} / \mathrm{mol})$ & $T_{\max }\left({ }^{\circ} \mathrm{C}\right)$ & $\mathrm{G}_{\max }{ }^{\prime}(\mathrm{kPa})$ \\
\hline DEP & 222 & $\sim 80$ & $\sim 220$ \\
DOP & 391 & $\sim 130$ & $\sim 50$ \\
DUP & 475 & $\sim 160$ & $\sim 13.5$ \\
\hline
\end{tabular}

chain stiffness and thus are expected to decrease $T_{\max }$. As expected, the $T_{\max }$ value of ASE is lower than the value of corresponding phthalate.

In the same way, the result obtained for EHBC would indicate that this plasticizer having ester groups in para position is more flexible than its ortho isomer (DOP). Accordingly, this plasticizer could be ranged in the adipate family.

The differences between aliphatic linear plasticizers (adipates) and branched plasticizers (citrates and esters of pentaerythritol) show that $T_{\max }$ is a decreasing function of the degree of branching.

Let us now consider maximum $\mathrm{G}^{\prime}$ values. They appear clearly as a decreasing function of $T_{\max }$. $G_{\text {max }}^{\prime}$ has been plotted against $M$ in Figure 4. $\mathrm{G}_{\max }^{\prime}$ appears as a pseudo exponential function of molar mass for phthalates [filled (linear) and empty (branched) squares in Figure 4], but the nature of the dependence is less clear for the other plasticizer families, which are however distinguishable from phthalates.

Table III. Coordinates of the Maximum of Storage Shear Modulus

\begin{tabular}{llll}
\hline Plasticizer & $\begin{array}{l}\text { Molar mass } \\
(\mathrm{g} / \mathrm{mol})\end{array}$ & $\begin{array}{l}\text { Temperature } \\
\max (\mathrm{K})\end{array}$ & $\begin{array}{l}\text { Maximum } \mathrm{G}^{\prime} \\
(\mathrm{kPa})\end{array}$ \\
\hline DEP & 222 & $348(346)$ & 214 \\
HNUP & 418 & $405(407)$ & 34.5 \\
NUP & 450 & $416(417)$ & 23.4 \\
DUP & 475 & $424(424)$ & 13.2 \\
DIBP & 278 & $358(363)$ & 148 \\
DOP & 391 & $397(398)$ & 48.6 \\
DINP & 421 & $406(408)$ & 21.3 \\
DHA & 314 & $388(386)$ & 41.5 \\
DINA & 398 & $419(420)$ & 10.4 \\
PA3 & 3300 & 411 & 36.3 \\
PA7 & 7000 & 411 & 43.3 \\
ATBC & 402 & $397(394)$ & 54 \\
ATHC & 486 & $411(416)$ & 23.4 \\
ASE & 368 & $386(391)$ & 75.1 \\
\hline EHBC & 391 & $413(398)$ & 22.5 \\
DINCH & 425 & & 15.7 \\
H600 & 604 & $420(412)$ & 15.5 \\
\hline H707 & 750 & $427(438)$ & \\
\hline
\end{tabular}

Calculated values between parentheses.

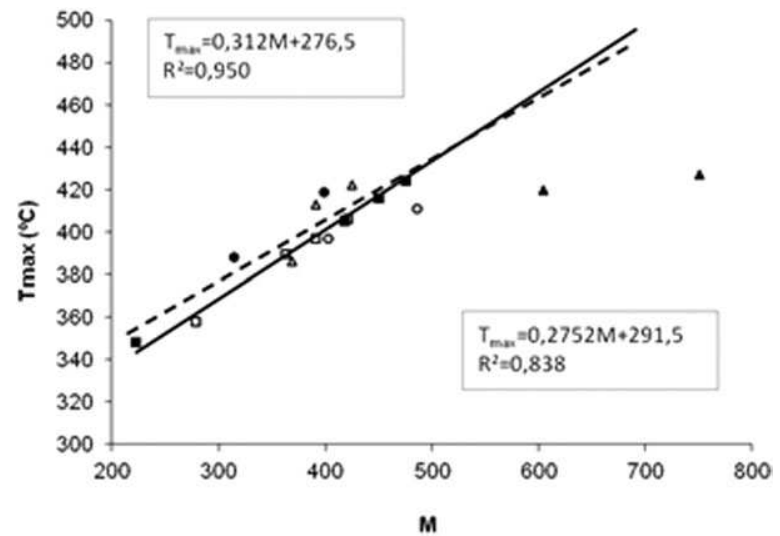

Figure 3. Temperature of maximum modulus against plasticizer molar mass. Linear phthalates, $\square$ branched phthalates, $\bigcirc$ adipates, $\square$ citrates, $\boldsymbol{\Delta}$ esters of pentaerythritol, and $\triangle$ others.

\section{DISCUSSION}

Let us consider first the mechanisms responsible for modulus variations independently of plasticizer nature. The discussion can be based on three striking facts: the sharpness of modulus increase, the absence of a shoulder at approximately $80^{\circ} \mathrm{C}$ previously observed for plasticized homopolymer samples studied at higher rates of temperature increase, ${ }^{1,2}$ and the clear separation between the exotherm observed in DSC thermograms and the modulus peak (Figure 5). The DSC exotherm can be attributed to the plasticizer dissolution into PVC particles. For all the plasticizers under study, this dissolution is almost complete at the onset of gelation otherwise a shoulder because of unplasticized PVC would remain at about $80^{\circ} \mathrm{C}$. It appears clearly that the appearance of an elastic component in the rheological behavior of the material can be decoupled from the dissolution process. Among hypotheses about this mechanism, PVC particle swelling was proposed. ${ }^{18}$

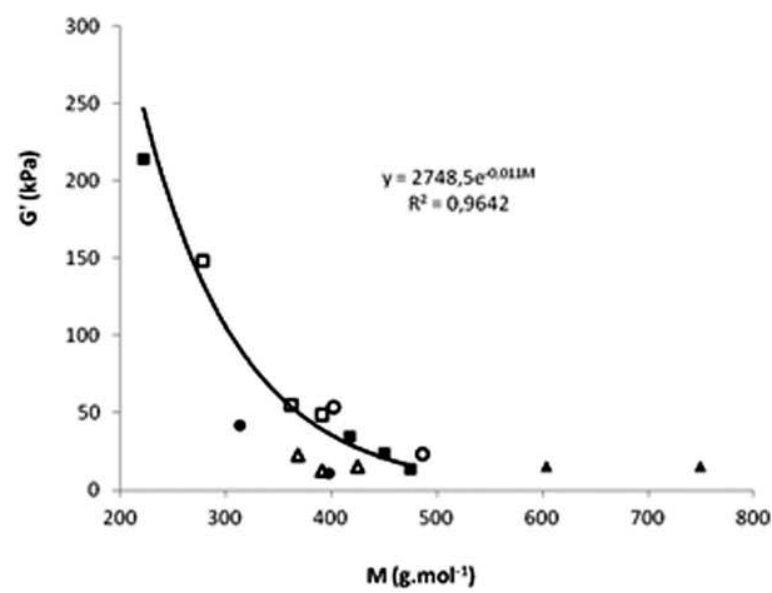

Figure 4. Maximum G' modulus against plasticizer molar mass. L Linear phthalates, $\square$ branched phthalates, $\bigcirc$ adipates, - citrates, $\boldsymbol{\Delta}$ esters of pentaerythritol, and $\triangle$ others. The equation corresponds to the phthalate plasticizers. 


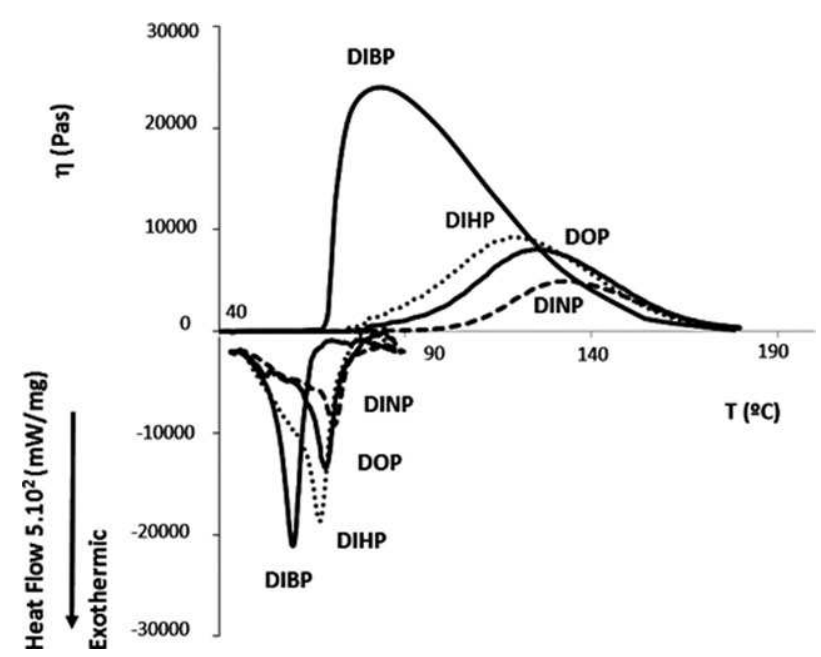

Figure 5. DSC exotherm (multiplied by $5 \times 10^{2}$ ) and complex viscosity variation for the DIBP, DIHP, DOP, and DINP systems.

The dissolution process has been described as a progressive "invasion" of polymer particles by the plasticizer, leading to a swelling ratio presumably close to 2 , assuming additivity of polymer and plasticizer volumes at equilibrium. It is well known that for a suspension of rigid spherical particles, viscosity obeys Einstein law at high dilutions:

$$
\frac{\mathrm{d} \eta}{\mathrm{d} v}=\frac{5 \eta_{\mathrm{s}}}{2}
$$

where $v$ is the solid volume fraction and $\eta_{\mathrm{s}}$ is the solvent viscosity. Here, however the volume fraction of swelled particles can approach unity and Einstein law is no longer valid. For rigid spherical particles, the viscosity diverges at a critical volume fraction close of 0.6 . Its variation can be represented by equations as the following one:

$$
\frac{\eta}{\eta_{s}}=\frac{1}{\left(1-v / v_{0}\right)^{2}}
$$

where $v_{0}$ is approximately 0.6 . In this case, one would observe the sudden appearance of elastic properties when $v$ approaches $v_{0}$, which can be considered as a percolation threshold. Here, however, the particles are neither spherical nor rigid in their superficial layer. Little is known on elastic properties of such systems where viscosity probably increases continuously but does not diverge.

Figure 5 shows in the same graph the evolution of the complex viscosity (positive $y$-axis) and the heat evolved (negative part of the $y$-axis) as a result of the interaction of the plasticizer with the resin for the plastisols prepared with DIBP, DIHP, DOP, and DINP. It can be observed that there is an important delay between the peaks of the two parameters. There are two possibilities to explain such a delay: In the first one, swelling continues because solvent absorption by particles continues. In this case, it would remain to explain why plasticizer absorption is exothermic at the beginning of the process and athermic in its last steps that is not obvious. The second possibility corre- sponds to the case where swelling would be delayed relatively to dissolution in other words that swelling would display strong viscoelastic effects. The existence of a viscoelastic character of swelling is attested by the development of swelling stresses, ${ }^{22}$ but these phenomena, which affect the plasticizer diffusion into PVC, occur in shorter times than modulus rise ones. These arguments led to abandon the hypothesis of swelling as the main cause of modulus increase. Swelling is probably responsible for a viscosity increase during dissolution, but the corresponding changes are too small to be detected by rheometry in the conditions under study.

The hypothesis of plasticizer evaporation can also be rejected on the basis of thermogravimetric experiments ${ }^{23}$ showing that mass losses are negligible, in the temperature interval and for the temperature ramp under study, except for the lighter plasticizers (DEP and DIBP) for which limited mass losses, without noticeable consequences on rheological properties, can occur.

Certain authors ignored the mechanism of modulus increase but focused on the maximum, which was considered as a melting point. Lopez et al. ${ }^{20}$ based their theory on two observations: unplasticized PVC displays a small endotherm near to $170^{\circ} \mathrm{C}$, and mechanical analysis on processed samples shows that good mechanical properties (ductility in tension) can be achieved only if a temperature higher than $160^{\circ} \mathrm{C}$ is reached in he final phase of processing. Furthermore, the above-mentioned endotherm has disappeared in processed samples. These observations were explained as follows: PVC displays a crystallinity linked to the presence of a small quantity of long syndiotactic sequences. The crystallinity ratio is generally lower than $5 \%$; crystallites are presumably of the fringed micelle type and they behave as physical crosslinks. At the melting point, there is a collapse of the network formed by crystallites and a concomitant decrease of modulus.

The following arguments militate against this theory: (i) melting is generally abrupt whereas modulus (or viscosity) variations observed here are rather progressive; (ii) the melting point would be sharply dependent of plasticizer nature: from $348 \mathrm{~K}$ (DEP) to $427 \mathrm{~K}$ (H707). This dependence would be very difficult to explain; (iii) no melting endotherm was observed in our samples in which it can be recalled that supplementary structural disorder, opposite to crystallization, is created by the presence of the comonomer VAC.

Only one possibility to explain the observed behavior remains to our knowledge: the occurrence of interparticle welding by chain diffusion. Let us recall that at the end of the first step of dissolution, we are in the presence of strongly swollen particles, occupying almost all the sample volume, with plasticizer molecules moving freely from one particle to another. But polymer chains, of which the diffusion is considerably slower with higher activation energy, remain temporarily confined in their original particle. When temperature increases however, chain diffusivity increases and macromolecules belonging to a given particle begin to penetrate by reptation in the neighboring particles where they entangle progressively with the host chains, inducing interparticle adhesion and thus increasing viscosity (Figure 6). 
(a)

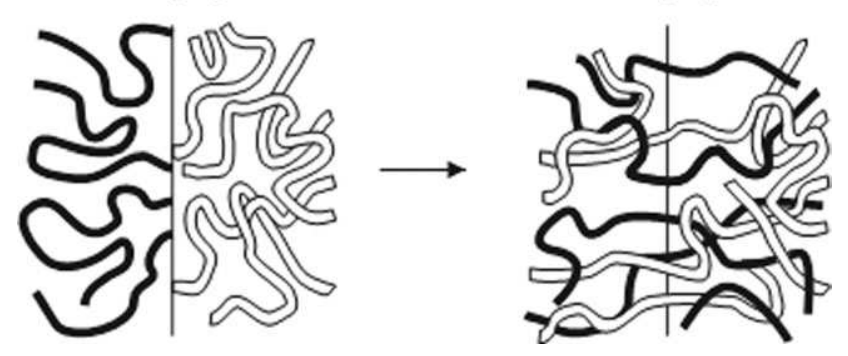

Figure 6. Schematization of interparticle welding by chain reptation and entanglement. (a) initial state and (b) state chain diffusion through interface.

The material, which was initially a fluid of independent particles in a solvent (the plasticizer), becomes progressively a network of particles "welded" one to another by chain entanglements. Here, it is licit to use the term of "gelation," which corresponds to the state where the particles network reaches a percolation threshold (Figure 7). ${ }^{19}$ Gelation is a relatively sudden phenomenon that explains the fast modulus rise.

Beyond a certain time, particles become undistinguishable, chains and plasticizer molecules are homogeneously distributed in the whole sample volume, and the initially biphasic material has been converted into monophasic material.

It seemed to us interesting to estimate the plateau modulus of unplasticized PVC at $400 \mathrm{~K}$, that is, in the region of interest, using Flory's relationship ${ }^{24}$ : where $\rho$ is the density $(\sim 1200 \mathrm{~kg}$ $\left.\mathrm{m}^{-3}\right), v$ is the volume fraction of PVC $(\sim 0.4)$, and $\mathrm{Me}$ is the entanglement molar mass $\left(6.2 \mathrm{~kg} \mathrm{~mol}^{-1}\right.$ according to Van Krevelen). ${ }^{25}$ One obtains $\mathrm{G}_{\mathrm{PVC}}^{\prime} \sim 475 \mathrm{kPa}$.

One sees that $G_{\max }^{\prime}$ remains lower than $G_{P V C}^{\prime}$ but tends to approach this value for the lighter plasticizers.

Entanglements are not permanent; they are characterized by a lifetime that is a decreasing function of temperature and presumably of plasticizer structure through friction effects. Beyond a certain temperature, this lifetime becomes shorter than the characteristic time of measurement and the material becomes a liquid of which the viscosity is a decreasing function of temperature. Finally, the trajectory of the representative point of the system in the modulus-temperature/time space can be decomposed into four periods. In the first one, where swelling is negligible, the sample viscosity, sharply linked to plasticizer viscosity,

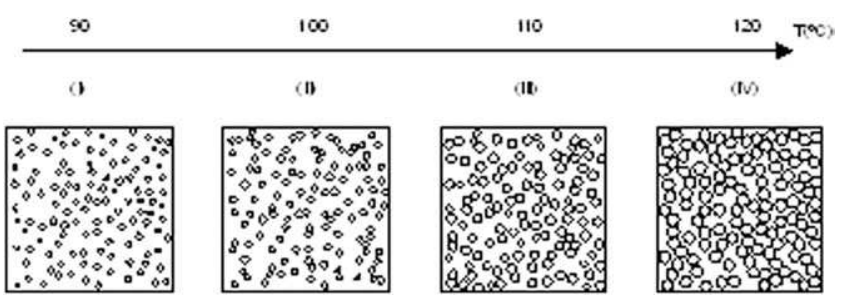

Figure 7. Schematic representation of the gelation process by particle welding. The gel point would correspond to phase IV where the percolation threshold is reached. The temperatures would tentatively correspond to the PVC-DOP system.

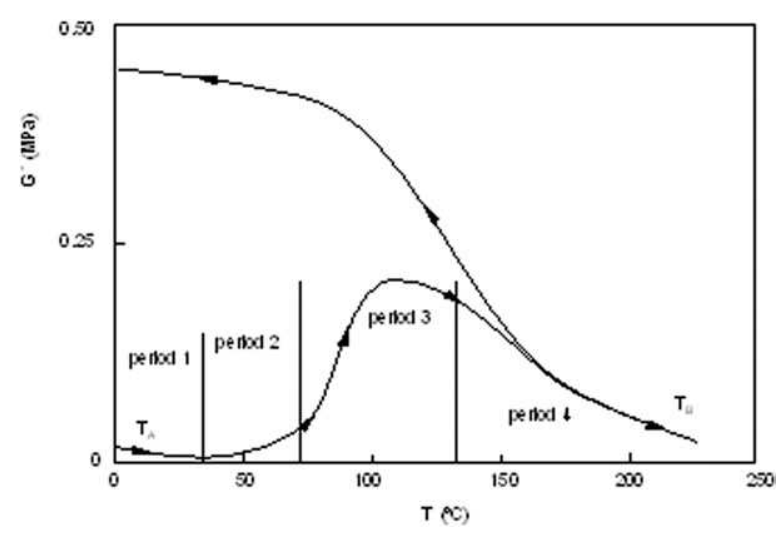

Figure 8. Presumed shape of modulus-temperature curves in a temperature cycle: $T_{\mathrm{A}}-T_{\mathrm{B}}-T_{\mathrm{A}}$.

decreases. The second one corresponds to dissolution and particle swelling. During this period, viscosity increases but remains low. The sample does not display elastic properties during these two periods. The third period corresponds to particle "welding" by chain diffusion. The phenomenon accelerates as the system approaches gelation. However, chain disentanglement rate also increases and becomes predominant above a certain temperature, which corresponds to the modulus maximum and the beginning of the fourth period. Shortly after the maximum, the material becomes homogeneous. If the sample was cooled down to $T_{\mathrm{A}}$, its modulus-temperature curve would follow the upper part of the curve in Figure 8 and such curve would become undistinguishable from a curve recorded in a second run (Figure 8).

The (more or less diffuse) transitions between the above-defined phases depend, indeed, on the chosen temperature gradient and measurement frequency.

From the thermodynamic point of view, it is important to remark that only the first phase involves heat exchange, the second phase is athermic, which is not surprising considering the small composition changes occurred.

The kinetics of modulus changes must essentially depend on chain diffusivity, whereas in the first step, dissolution rate was found to depend essentially on plasticizer diffusivity. Polymer diffusivity is expected to depend mainly on three structural factors: the weight average molar mass $\mathrm{Mw}$ of the polymer, the plasticizer volume fraction, and the polymer-plasticizer friction coefficient. ${ }^{26}$ This latter presumably increases with the plasticizer molar mass. The rubbery plateau modulus depends only on entanglement molar mass and plasticizer volume fraction; it is independent, at first order, of the plasticizer molar mass. The curves modulus versus temperature of homogeneous polymerplasticizer mixtures differing by plasticizer structure must have the shape of Figure 9.

First, run experimental curves are presented in the same figure. In the low temperature domain, the plasticizer molar mass plays a double role: first by its link with plasticizer viscosity $\eta_{s}^{*}$ (eq. (3)), second by its role on chain diffusion through friction coefficient. Both effects influence viscosity in the same sense that can explain the strong effect of plasticizer molar mass on rate of 


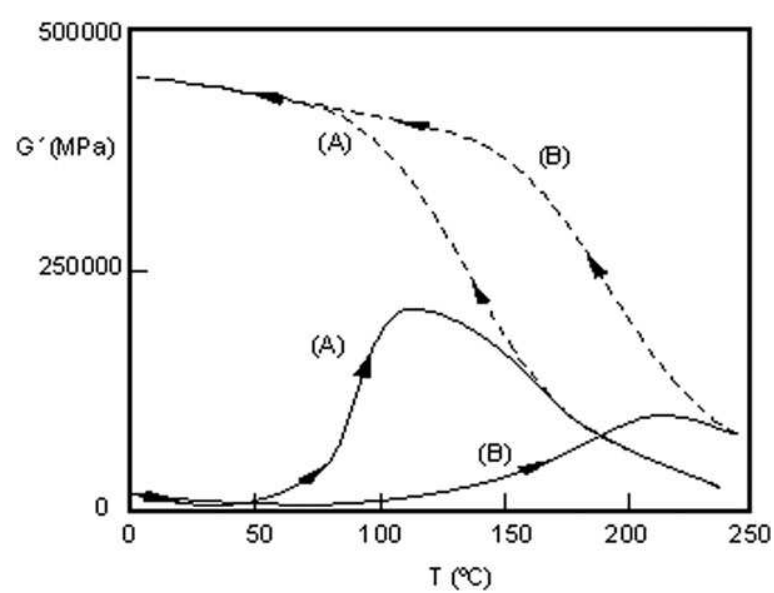

Figure 9. Modulus versus temperature curves for starting samples (full lines) and homogenized samples (dashed lines) for a light plasticizer (A) and a heavy plasticizer (B).

viscosity increase. If particle welding is slower, the curve modulus-temperature rejoins the curve of homogeneous sample in the "visco-plastic" region, latter, at lower modulus value.

For a given molar mass value, it has been shown that there are differences between linear (phthalates and adipates) and branched (citrates and pentaerythritol esters) molecules. Such differences could be tentatively explained by an effect of branching on polymer-plasticizer friction coefficient. A similar hierarchy was found in the study of the dissolution exotherm not reported here. It can be attributed to the key role of plasticizer diffusivity into the polymer. If friction plays a role on polymer diffusion, it is not unreasonable to suppose that it plays also a similar role on plasticizer diffusion into the polymer.

It is noteworthy that if modulus changes result from a kinetic process, time can be a more pertinent variable than temperature, both being linked by the heating program:

$$
T=320+0.0833 t, \quad \text { i.e., } t=12 T-3840
$$

The time $t_{\max }$ to reach the viscosity maximum would vary from $300 \mathrm{~s}$ (DEP) to $1296 \mathrm{~s}$ (H700).

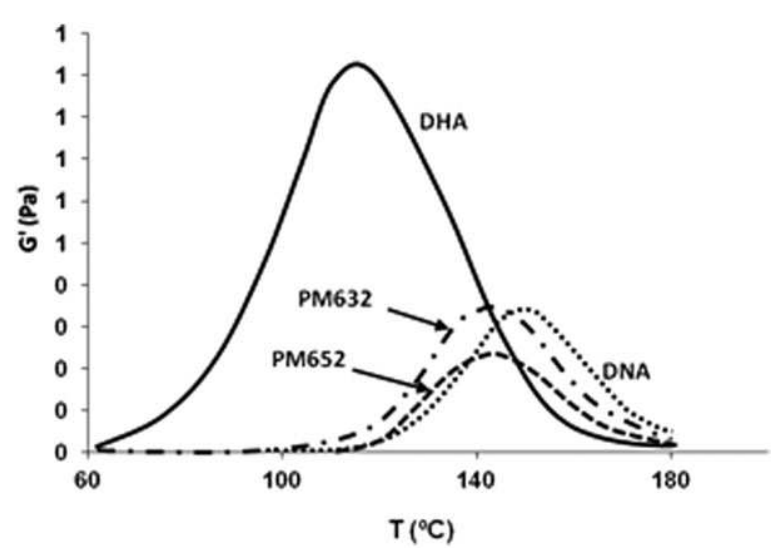

Figure 10. Superposition of modulus-temperature curves for polyadipates and for molecular adipates.
(A)

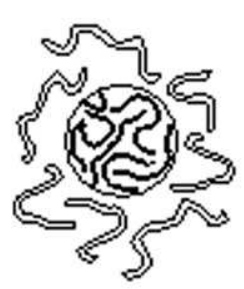

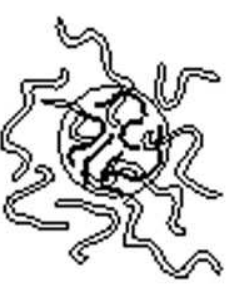

(B)

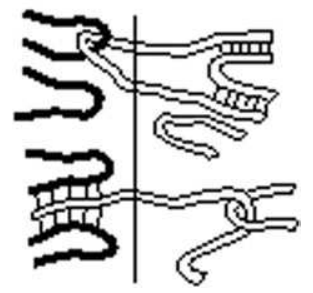

Figure 11. Schematization of PVC-polyadipate interaction. (A) at the particle dimension scale showing partially sorbed chains. (B) at chain dimension scale showing entanglements on both sides.

The importance of diffusion processes is clearly confirmed by the results of García and Marcilla ${ }^{10-13}$ showing the tremendous influence of particle size and polymer molar mass on modulus and viscosity changes on such systems. An increase of particle size has qualitatively the same effect as an increase of plasticizer molar mass. Let us recall that the characteristic time $t_{\mathrm{D}}$ of fickian diffusion is:

$$
t_{D}=\frac{L^{2}}{D}
$$

where $L$ is the length of the diffusion path, here the particle radius.

Concerning the effect of the polymer chain length, García and Marcilla ${ }^{18}$ observed that the temperature to reach a modulus value of $50 \mathrm{kPa}$ was about $90^{\circ} \mathrm{C}$ for $\mathrm{Mw} \sim 102 \mathrm{~kg} \mathrm{~mol}^{-1}$ and about $112^{\circ} \mathrm{C}$ for $\mathrm{Mw}=144 \mathrm{~kg} \mathrm{~mol}^{-1}$. This very strong effect can be linked to the phenomenon of chain diffusion by reptation of which the characteristic time is roughly proportional to the cube of Mw.

Let us now consider the case of polymeric plasticizers $(\mathrm{M} \geq$ $3300 \mathrm{~g} \mathrm{~mol}^{-1}$ ) (Figure 10, monomeric adipates are also shown).

Surprisingly, the modulus rise is considerably faster than predicted from the above observed structure-property relationships. This peculiarity can be also explained by considerations of chain reptation. At every step of periods II and III, there are plasticizer chains partially engaged in PVC particles, having one extremity entangled with PVC chains and the other extremity immersed in the polyadipate matrix or the reverse situation (Figure 11).

Polyadipate chains entangled on both sides must be rare owing to the chain shortness. In both cases, however, the polyadipate chain portion "floating" in the polyadipate matrix must play a particle-matrix coupling role by physical crosslinking or simply by friction. At the same state of polymer-plasticizer interpenetration, molecular plasticizers have not such role. Schematically, partially solvated polymeric plasticizers have the same influence on viscosity as totally solvated molecular plasticizers.

\section{CONCLUSION}

The rheological properties of 19 samples of PVC-plasticizer (1/ 1) mixtures differing only by the plasticizer structure have been 
studied in programmed temperature $\left(5 \mathrm{~K} \mathrm{~min}^{-1}\right)$ between 40 and $180^{\circ} \mathrm{C}$. Viscosity increases long time after the end of the dissolution process, reaches a maximum, and then decreases. At the same time, plasticizer penetrates and swells the particles until the time where the material becomes a homogeneous visco-plastic liquid.

The above considerations led us to suggest the possibility of "welding" of swelled particles by chain reptation as responsible for the viscosity increase experimentally observed.

The plasticizer nature would influence chain diffusion through its influence on friction parameter. The higher the molar mass, stiffness, and/or degree of branching of the plasticizer molecule, the slower the chain diffusion and the viscosity increase, and the longer the time to sample homogenization. As a result, the temperature at the maximum viscosity increases with the three above-cited plasticizer characteristics.

\section{REFERENCES}

1. Nakajima, N.; Harrell, E. R. Adv. Polym. Technol. 1986, 6, 409.

2. Daniels, P. H.; Brofman, C. M.; Haarvey, G. D. J. Vinyl Technol. 1986, 8, 160.

3. Nakajima, N.; Kwak, S. Y. J. Vinyl Technol. 1991, 13, 212.

4. Daniels, P. H. J. Vinyl Additive Technol. 2007, DOI 10.1002/ vol.20119.

5. Persico, P.; Ambrogi, V.; Acierno, D.; Carfagna, C. J. Vinyl Additive Technol. 2009, DOI. 10.1002/vol.20187.

6. Ramos-Devalle, L.; Gonzalez-Roa, C.; Sanchez-Adame, M.; Zamora-Rodriguez, J. J. Vinyl Technol. 1992, 14(2), 74.

7. Alfrey, T.; Gurnee, C. F.; Lloyd, W. G. J. Polym. Sci. 1966, 12, 249.
8. Thomas, N.L.; Windle, N. H. Polymer 1972, 23, 529.

9. Fenollar, O.; Garcia, D.; Sanchez, L.; Lopez, J.; Balart, R. Eur. Polym. J. 2009, 45, 2674.

10. García, J. C.; Marcilla, A. Polymer 1998, 39, 3507.

11. Jourdan, J. S.; Owen, D. P. J. Vinyl Additive Technol. 2008, 14, 99.

12. Nakajima, N.; Isner, J. D.; Harrell, E. R. J. Macromol. Sci. Phys. 1981, B20, 349.

13. Marcilla, A.; García, J. C. Eur. Polym. J. 1998, 34, 1341.

14. Marcilla, A.; García, J. C. Eur. Polym. J. 1997; 33, 349.

15. Boudhani, H.; Laine, C.; Fulchiron, R.; Cassagnau, P. Rheol. Acta 2007, 46, 825.

16. Willey, S. J.; Macosko, C. A. J. Rheol. 1978, 22, 525.

17. Willey, S. J.; Macosko, C. A. J. Rheol. 1982, 26, 557.

18. Marcilla, A.; García, J. C. Polymer 1998, 39, 431.

19. Boudhani, H.; Fulchiron, R.; Cassagnau, P. Rheol. Acta 2009, 48, 135.

20. López, J.; Balart, R.; Jiménez, A. J. Appl. Polym. Sci. 2004, 91, 538.

21. Gilbert, M. J Macromol. Sci. 1994, 34, 77.

22. Argon, A. S.; Cohen, R. E.; Patel, A. C. Polymer 1999, 40, 6991.

23. Zoller, A.; Marcilla, A. J. Appl. Polym. Sci. 2012, 124, 2691.

24. Flory, P. J. Principles of Polymer Chemistry; Cornell University Press: Ithaca, 1953.

25. Van Krevelen, D. W.; Nijenhuis, K. Properties of Polymers: Their Correlation with Chemical Structure their Numerical Estimation \& Prediction from Additive Group; Elsevier (4th edition), Amsterdam, 2009.

26. De Gennes, P. G. Scaling Concepts in Polymer Physics; Cornell University Press: Ithaca, 1979. 